\title{
O direito à cidade e a produção do espaço entre discursos: a luta pela significação na "recuperação" de ambientes urbanos
}

\author{
The Right To The City And Production Space Between Discourses: \\ The Fight For Signification Of Recovery Urban Environments
}

Carlos César de Oliveira Lacerda, Sérgio Carvalho Benício de Mello

Universidade Federal de Pernambuco (UFPE), Recife, PE, Brasil

\section{Resumo}

O objetivo desse trabalho é analisar as estruturas discursivas, por meio da ontologia do discurso, as demandas inerentes ao espaço urbano do Cais Mauá em Porto Alegre-RS, identificando os elementos e os significados que estão em toda a negociação do espaço. Para isso, foi montado um corpus de pesquisa contendo 184 arquivos, dentre eles: reportagens, entrevista, imagens, vídeos, áudios e documentos que foram analisados a fim de desvelar os discursos a partir de um antagonismo social. Sob uma perspectiva pós-estruturalista, foi utilizada a Teoria do Discurso (TD) de Laclau e Mouffe que permitiu investigar a construção da realidade social constituída por discursos com o aparato da teoria auxiliar sobre o Direito à Cidade de Henri Lefebvre, além dos estudos sobre a Produção Capitalista do Espaço de David Harvey, através de uma metodologia retrodutiva. Foi constatado que as práticas discursivas revelam um conflito entre a postura hegemônica e a contra hegemonia. As cadeias de equivalências e diferenças demonstram que o Cais Mauá disputa significados através de suas peculiaridades, mas que compartilham algo em comum: o conceito de cidade de um lado referente à mega estruturas, grandes empreendimentos e valor econômico agregado rumo ao progresso, e do outro lado em participação, transparência, convívio e preservação, através de [r] existência, estratégias e outras alternativas de requalificação.

Palavras-chave: Requalificação. Cais Mauá. Teoria do discurso. Conflitos. Direito à cidade.

\begin{abstract}
The aim of this study is analyse demands inherent to Pier Mauás urban space in Porto Alegre-RS through discursive structures, identifying elements and meanings that are present throughout urban space debates. For this, a research corpus was assembled containing 184 files, including: papers, interviews, images, videos, audios and documents that were analysed in order to better understand discourses from a social antagonism's
\end{abstract}

CCOL é Pesquisador, Mestre em Administração, e-mail: cesarlacerda.adm@hotmail.com SCBM é Professor associado, PhD in Business Studies, e-mail: sergio.benicio@gmail.com 
point of view. Under a post-structuralist perspective, Laclau and Mouffe's Discourse Theory (TD) was used as it allows a socio-political analysis of society. Some auxiliary theories regarding the Right to the City from Henri Lefebvre was also considered as well as David Harvey's Capitalist Production of Space. Following the tradition of TD studies, a retroductive methodology was performed. Our findings revealed a conflict between the hegemonic posture adopted by those who want to reshape Pier Mauá into a commercial and entrepreneurial area and those who, with a counter hegemonic posture, defend the maintenance and requalification of its area contemplating it as a public space ideal for leisure, culture and tourism. It was also possible to identify some equivalences considering Pier Mauá's disputes around: the concept of City - on the one hand, related to mega structures, large enterprises and economic value towards progress and, on the other hand, participation, transparency, community and preservation through [r]existence strategies and other alternatives regarding the state of urban space being qualified for people and not for businesses.

Keywords: Requalification. Pier Mauá. Discourse theory. Conflicts. Right to the city.

\section{Introdução}

Discutir as demandas sociais e os espaços públicos começa a fazer sentido quando se compreende as várias articulações e os discursos que existem em determinado contexto, isto é, a organização pode ser concebida como sinônimo das mais diversas formas de se organizar, indo até a apropriação dos espaços da cidade. Posições antagônicas, articulação, conflitos, espaços, demandas sociais, planejamento urbano e o direito à cidade a princípio parecem conceitos espaçados, mas sob a ótica da teoria do discurso e seu pós-estruturalismo existem ligações e reflexões entre eles.

A temática sobre a requalificação de espaços urbanos tem se tornado algo frequente diante das novas configurações em torno da cidade. Cada vez mais as áreas centrais estão sendo requalificadas por conta do esvaziamento de suas funções, do abandono de algumas edificações históricas e pela mudança de hábito da sociedade (Kruse, 2011). No entanto, esses espaços ainda possuem relevância simbólica e fazem parte de um imaginário popular, gerando expectativas na imagem do centro (Del Rio, 1993). No Brasil: o caso da cidade de Salvador-BA, Santos-SP, Recife-PE, Maceió-AL e Vitória-ES (Cardoso, 2007). Nesse sentido, o objeto de estudo deste trabalho foi o espaço público do porto Cais Mauá, localizado na cidade de Porto Alegre-RS. Especificamente o projeto pretende "revitalizar" o porto.

O Cais Mauá é um porto localizado ao lado do Centro Histórico de Porto Alegre-RS e faz parte da história da cidade cujas características especiais o fizeram ser protegido pelos Patrimônios Histórico Nacional e Municipal. A importância histórica do Cais Mauá reside no fato de sua construção resultar de um grande esforço conjunto entre o governo e a sociedade gaúcha, que se empenhavam, no início do século XX, para modernizar a capital e incrementar a economia. o Cais Mauá faz parte da história da cidade e a localização do porto é motivo de interesse da iniciativa privada, pois se encontra em local estratégico para atrair turistas (Vieira, 2011).

Ao longo dos anos, vêm sendo discutidos projetos para requalificar o local e depois de várias tentativas, em 2010 foi lançado Edital de Concorrência 001/2010, para aprovação das propostas de requalificação do Cais Mauá. 0 projeto vencedor da concorrência deverá observar e priorizar a acessibilidade, o restauro do patrimônio histórico e a realocação dos prédios públicos atualmente existentes. No final do referido ano foi assinado contrato entre a Cais Mauá do Brasil S.A. (um grupo de organização privada formada por uma empresa brasileira e três empresas européias), vencedora da concorrência, e o Governo do Estado para a requalificação do Cais (Vieira, 2012).

Assim, o espaço começa a ser alvo de polêmicas devido à proposta grandiosa de requalificação. Em 2015, o Cais Mauá foi objeto de discussões referente a esse projeto por grupos que se manifestaram contra ao projeto aprovado, ou seja, demonstrando que a requalificação não é uma unanimidade para a população.

Com o intuito de resistir ao projeto surgiu, por exemplo, o movimento Cais Mauá de Todos, dentre outros movimentos que defendem a ampla participação 
popular na discussão e total transparência em relação à parceria público/privada. As notícias da mídia e os movimentos de resistência foram ganhando espaços de discussão como forma de demonstrar o descontentamento dos vários grupos contra esse projeto. Observam-se assim, que os ambientes midiáticos por meio de jornais locais, reportagens e redes sociais se tornaram um espaço para as discussões que envolvem a problemática, como também as explicações referentes ao projeto urbanístico na cidade, ou seja, o que se pode inferir é que as questões de cidadania e democráticas estão presentes neste contexto, denotando a participação popular nessas discussões.

Diante desse debate, alguns questionamentos são pertinentes e são apontados como possíveis problemáticas neste trabalho: qual tipo de requalificação foi proposta para a sociedade? Quais os interesses principais da proposta? Quais os atores envolvidos nessa disputa? Como os sujeitos políticos estão se organizando? Cidade pra quem? Essa revitalização contou com a participação social? Quais os interesses que estão por trás desse projeto? Essas são algumas questões que o presente trabalho tenta refletir, considerando uma pergunta central norteadora do estudo: Como é possível pensar a requalificação do Porto Cais Mauá, atendendo as demandas dos grupos sociais envolvidos, sem degradar o patrimônio histórico e cultural, pautado na ideia do direito à cidade?

Acredita-se então, que as disputas que envolvem o espaço do Cais Mauá se dão para tornar o espaço mais atrativo, de convivência e preservando sua memória, dando um novo sentido ao espaço e tornando-o um lugar para todos. Por enquanto essa é a hipótese inicial $\left(\mathrm{H}^{1}\right)$ do presente trabalho. Assim, pretende-se desvelar os antagonismos existentes na luta pelo espaço público, captando as vozes para desvendar as ontologias presentes no espaço após as análises dos discursos dos atores envolvidos na disputa.

0 objetivo que norteia este trabalho foi analisar as estruturas discursivas, através da ontologia do discurso, as demandas inerentes ao espaço urbano do Cais Mauá, identificando os elementos e os significados que estão em toda a negociação do espaço. A abordagem foi a partir da Teoria do Discurso de Ernesto Laclau e Chantal Mouffe, uma teoria pós-estruturalista de matriz pós-marxista que problematiza os discursos, considerando-o como uma prática social.

Essa abordagem possui uma "centralidade em sua percepção do discurso, com raízes em alguns dos principais desenvolvimentos filosóficos, como por exemplo, a filosofia analítica, a fenomenologia e o estruturalismo" (Silva et al., 2014, p. 75). Paralelamente essa discussão também foi apoiada na teoria do Direito à Cidade de Henri Lefebvre e nos estudos sobre a Produção Capitalista do Espaço de David Harvey a partir de uma metodologia Retrodutiva (Glynos \& Howarth, 2007) a qual está detalhada na sessão metodológica.

\section{O Cais Mauá como arena de lutas: memória, "Requalificações" e o Direito à cidade}

"Um Porto Alegre" como muitos estão chamando essa requalificação apresenta como objetivos uma requalificação para fins empresariais, de turismo, de lazer e cultural. 0 debate sobre a requalificação do Cais ocorre desde o final dos anos 1980, entretanto, esses projetos não conseguiram sucesso devido às articulações em torno do local. Somente em 2010 o "Projeto Cais Mauá do Brasil" venceu o edital e assim, começou o trabalho que até hoje enfrenta problemas de execução (Vieira, 2012).

O Cais projetado pelo grupo vencedor pretende dar à cidade de Porto Alegre uma cara mais sofisticada no sentido de atração turística. Conforme o Governo, Porto Alegre e o Cais Mauá deveria ser a sala de visitas do Estado do Rio Grande do Sul (Souza, 2008). A proposta de requalificação procura agregar novos usos para este espaço e, colocar Porto Alegre no contexto de consumo cultural, turístico e concorrência intercidades, através da política de intervenção no Cais a fim de projetar uma imagem de cidade inovadora e integrante das tendências do mundo globalizado.

O Cais, no futuro, seria dividido em três etapas: o Setor Gasômetro, o Setor Armazéns e o Setor Docas: 1) Gasômetro - que abarcará as atividades comerciais, como a construção de um shopping a fim de conectar o Rio Guaíba ao centro de compras e a Praça Brigadeiro Sampaio; 2) Setor Armazéns - neste setor encontram-se os bens patrimoniais, que serão utilizados para atividades culturais, gastronômicas, de lazer e educação; 3) Docas - têm como objetivo a implementação de atividades empresariais, como a construção de torres que abrigará um hotel, centro empresarial e estacionamentos (Figura 01). 


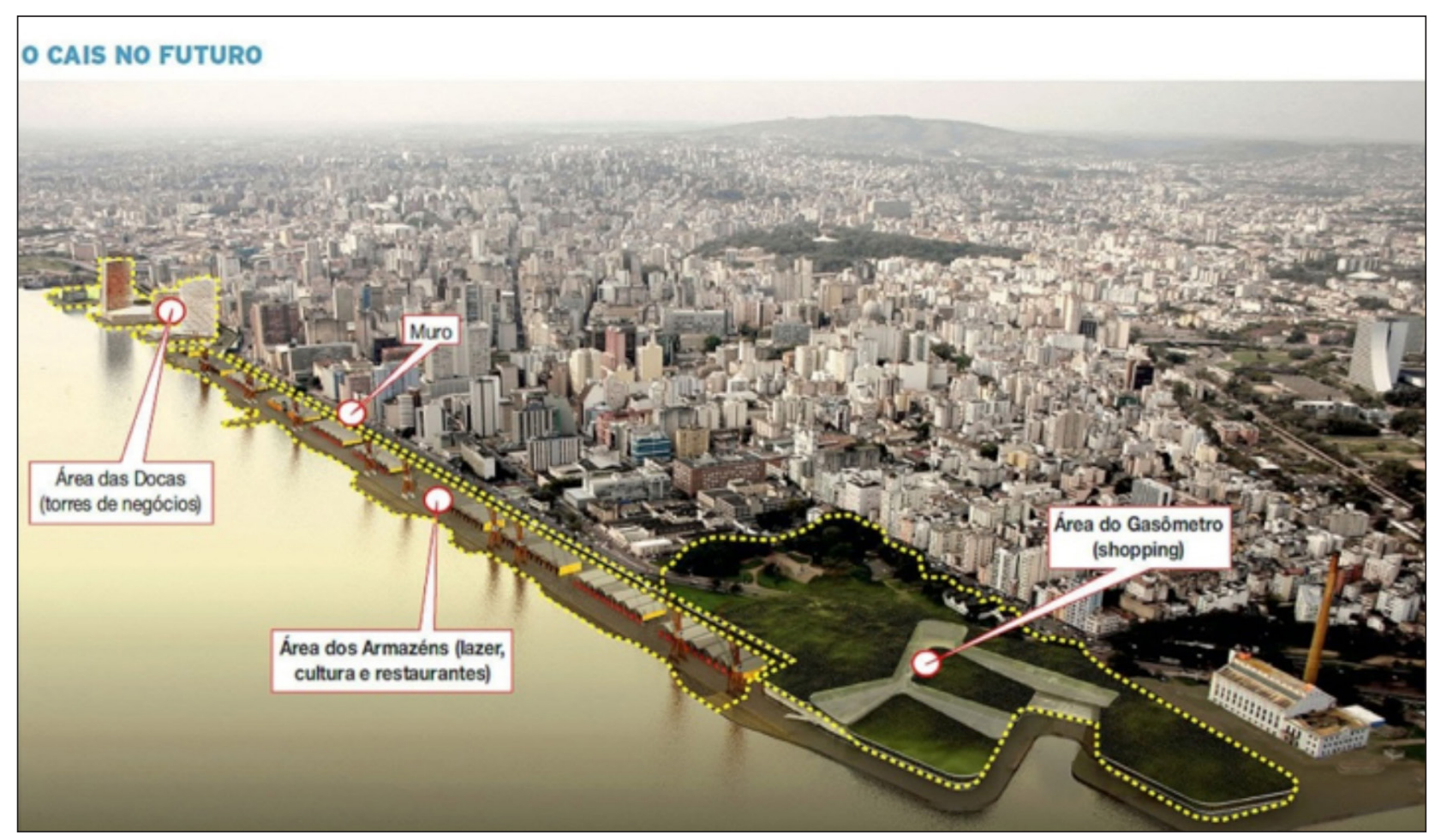

Figura 01- Projeção do projeto de requalificação do Cais Mauá. Fonte: Cavalheiro (2008).

Harvey (2005) chama atenção para este tipo de modernização, pois salienta que o processo de feitura da cidade, no capitalismo tardio, é tanto produto quanto condição dos processos de transformação da governança urbana, ou seja, de acordo com o autor a atividade é mostrada como espetáculo para aqueles que estão excluídos dela e se legitima configurando um novo imaginário de integração e memória. Observa-se uma visão empreendedora em relação ao desenvolvimento econômico, visando maximizar a atratividade local como chamariz para investimentos estrangeiros, megaeventos e grandes projetos urbanísticos, trazendo divisão no espaço e consequentemente desigualdade (Maziviero, 2016).

Dessa forma, é que o autor discute o termo "empresariamento urbano" que seria uma maneira de planejar e organizar a cidade, visando atender a diversos mercados, entre eles, o financeiro e o turístico. Nesse tipo de regime capitalista a cidade é reinventada para permitir o crescimento do capital, é o que ele chama de "cidade-mercadoria", ou seja, a cidade mostrada e vendida como produto no mercado, ignorando o espaço da vida cotidiana dos seus habitantes (Harvey, 2005). 0 trabalho de
Vieira (2011) aponta alguns questionamentos que faz uma reflexão de outras alternativas de requalificação, demonstrando uma posição crítica em relação ao tema do direito à cidade.

Depois de apresentado o projeto atual, o espaço como a ser alvo de polêmicas. Os grupos alegam divulgação e transparência pública, assim surgiram alguns grupos como "Cais Mauá de Todos", "A cidade que queremos" e "Ocupa Cais Mauá" que defendem a ampla participação popular na discussão, total transparência em relação à parceria público/privada e plena legalidade do processo (da licitação e concorrência até a celebração dos contratos). Nesse caso, esses grupos se apresentam como forças que reagem entre si, como em um campo de batalha, onde existem articulações que formam alianças com entidades flutuantes, mas, com interesses distintos (Pinto, 1999; Cordeiro \& Mello, 2013).

Para esses grupos essa requalificação que está sendo proposta não valoriza a memória da cidade e existe a supervalorização do solo urbano, agravando e expandindo problemas socioespaciais. Nesse sentido, Lefebvre (2008) discute o Direito à Cidade a partir de uma filosofia da cidade e do campo através 
de uma análise espectral em um ponto crítico. Para o autor, o direito a natureza é que faz parte dos hábitos sociais e o lazer comercializado, industrializado, organizado institucionalmente, destrói esta "naturalidade", indo de forma contraria ao direito à cidade.

A democratização do direito e a construção de um amplo movimento social para fortalecer seu desígnio é imperativo, se os despossuídos pretendem tomar para si o controle que há muito lhes tem sido negado, assim como se pretendem instituir novos modos de urbanização. Em outras palavras, o espaço urbano é produzido pelo homem a partir da forma que ele o percebe (experimenta), o concebe (pensa sobre) e o vive (age) (Lefebvre, 2008; Harvey, 2005).

Nessa análise, um Cais Mauá só funcionaria se essas três dimensões puderem ser atendidas de forma global: perceber no sentido sensorial, conceber no sentido de participar/planejar/ter voz e viver no sentido de fazer parte/vivência. Assim, para o autor, a revolução e a luta têm que ser urbana através do resgate histórico, cultural e político. Nesse caso, a cidade é um discurso e o discurso é uma linguagem, ou seja, uma comunicação e assim, a cidade se faz através de práticas sociais (Harvey, 2013).

\section{A abordagem da teoria do discurso e o antagonismo em torno do Cais Mauá: conceitos e categorias analíticas}

A Teoria do Discurso é uma teoria política que problematiza os sujeitos a partir das vozes (discurso), entendamos aqui que as vozes não são somente as falas, mas envolvem uma ampla gama de linguagens indo muito mais além, desvelando significados em torno dos acontecimentos, ou seja, o discurso nessa perspectiva precisa ser entendido como um sistema de significados contingentes inerentes as estruturas sociais (Cordeiro \& Mello, 2010; Foucault, 1996).

Os analistas do discurso Ernesto Laclau e Chantal Mouffe, na Escola de Essex, desenvolveram a teoria a partir da obra clássica Hegemony and Socialist Strategy publicada em 1985. Essa abordagem é de fundamento pós-estruturalista, numa releitura do conceito sobre hegemonia de Gramsci. Para os autores, a hegemonia abre alternativas para uma nova lógica do social e assim, novas perspectivas de análise, dessa forma, deve-se compreender o discurso como ontologia do social, marcado pelo antagonismo (Laclau \& Mouffe, 1985). Assim, a requalificação em torno do Cais a partir de suas demandas é uma construção social que precisa ser discutida através dos discursos.

A noção de hegemonia em Laclau \& Mouffe (2015) tem sua origem em Gramsci a partir de um conceito mais amplo para se discutir relações sociais. Para esse autor, a sociedade civil está representada em diversas classes, e existe sim luta dessas classes, mas não está representada em apenas uma categoria analítica. Para a teoria do discurso a hegemonia pode vir de qualquer lugar em uma análise política. Dessa forma, "significa foco de incessantes disputas entre os múltiplos discursos dispersos no campo da discursividade" (Mendonça, 2009, p. 160).

Um sistema discursivo é algo que engloba as diversas relações entre objetos e práticas, além de posições que os sujeitos assumem através das suas vozes, é dessa forma, que os significados são construídos e negociados formando um sistema. Assim sendo, o discurso não é algo apenas para ser desvendado e sim compreendido, discutido e problematizado através das várias possibilidades contingentes (Mendonça, 2009).

Os conflitos que estão em torno da requalificação do Cais Mauá podem ser considerados eventos por meio de articulações entre aqueles que apoiam o projeto e aqueles que consideram a requalificação um atentado contra o direito a cidade. Existe nesse caso, uma articulação entre os indivíduos. Articulação pode ser definida como "qualquer prática que estabeleça uma relação entre elementos de tal modo que sua identidade seja modificada como um resultado de prática articulatória" (Laclau \& Mouffe, 2015, p. 178).

Dessa forma, isso significa que qualquer tipo de prática que tenha relação entre seus elementos e que sua identidade é modificada pode ser resultado de uma prática articulatória. É nesse contexto que a requalificação do Cais Mauá está inserida, pois neste trabalho a análise se debruçou em discutir as práticas articulatórias através das posições dos sujeitos. Como se pode perceber, não existe diferença entre o discurso e prática, pois estas são resultados das leituras que cada agente faz embebido de ideologias (Coelho, 2012). 
Inseridos nessa articulação estão alguns conceitos que fazem parte da discussão em relação à teoria do discurso (elemento, momento e ponto nodal) que formam as categorias analíticas. Antes mesmo de existir a articulação existe os elementos que deixam de ser elementos quando se articulam, assumindo a condição de momento. Nesse sentido, os momentos dizem respeito às posições diferenciais que são articuladas em um discurso, já os elementos são as diferenças que não se apresentam discursivamente de forma articuladas, justamente por seu caráter flutuante (Silva et al., 2014).

Os pontos nodais para a Teoria do Discurso representam uma junção de momentos, fruto de articulações entre elementos, que inseridos no discurso geram assimilações a novas identidades capazes de gerar mudanças nas práticas discursivas. Assim, pode-se dizer que é o próprio sentido da prática articulatória (Mendonça, 2010; Laclau \& Mouffe, 2015). Isso significa que para esses autores, os pontos nodais são como pontos de referência em um determinado discurso que unem um sistema de significados numa cadeia de significação, ou seja, é aquilo que os discursos disputam para significar ou dar significado, neste caso, os discursos estão disputando para dar um significado à requalificação do Cais Mauá.

Esses pontos nodais são discutidos na visão de Laclau \& Mouffe (2015) com outro conceito aqui apresentado: os significantes vazios. "Um significante vazio, é, no sentido estrito do termo, um significante sem significado" (Laclau, 2011, p. 67). Ou seja, eles não possuem um significado estável e são capazes de se adequar de acordo com as demandas dos diferentes sujeitos políticos.

Os significantes vazios estão no campo do espaço no discurso e ao redor dos pontos nodais orbitam as identidades que disputam a oportunidade de preencher o espaço desses significantes vazios. No caso deste trabalho, o significante que está em disputa é o uso do espaço (Cais Mauá), onde existe uma luta entre as várias demandas existentes no processo articulatório. Resumindo, o ponto nodal é a requalificação (causa pela qual diferentes sujeitos políticos se reúnem) e o significante vazio é o uso do espaço Cais Mauá.

Outros dois conceitos abordados na Teoria do Discurso é o de cadeias de equivalência e diferença. Na visão de Laclau \& Mouffe (2015), a equivalência é através da lógica de simplificação do espaço político que expande o pólo pragmático, assim, reduzindo o número de possíveis posições do sujeito. Na diferença, se representa uma lógica que expande o pólo sintagmático, levando a um aumento da diversidade da posição do sujeito.

Cabe ainda discutir o conceito de posição do sujeito, este que é construído por meio dos discursos, podendo ocupar diferentes posições dependendo do contexto e das articulações (Mendonça, 2010). Em outras palavras, as equivalências são os grupos que possuem o mesmo discurso e estão se articulando para atingir suas demandas, já as diferenças aparecem depois que esses mesmos grupos chegam à hegemonia e suas particularidades começam a ficar visíveis, ou seja, fazem parte de um mesmo grupo, entretanto com demandas diferentes.

Por último, mas não menos importante, é discutido o conceito de antagonismo (conceito chave na relação entre objeto e teoria deste trabalho). Para a Teoria do Discurso um antagonismo é o "limite de toda a objetividade. Isso deve ser entendido em seu sentido mais literal: como a afirmação de que o antagonismo não tem um sentido objetivo, de modo que é aquilo que impede a constituição da objetividade como tal" (Laclau, 1993, p. 34).

Em outras palavras, o antagonismo ocorre por meio da negação de significados, dessa forma, o antagônico é sempre um discurso exterior; é sempre, um discurso com diferente positividade. De forma ainda mais complexa, na leitura de Laclau e Mouffe (2015) a presença do "outro" previne que eu seja totalmente eu. Isso significa que no antagonismo não existe nenhuma relação, ambos os lados são divergentes e não convivem entre si, diferentemente do conceito de agonismo onde as partes são divergentes, entretanto, reconhecem as demandas dos adversários (Mouffe, 2005). No caso do Cais Mauá, o antagonismo se apresenta na luta entre os elementos que se posicionam favoráveis à requalificação e aqueles que são desfavoráveis ao projeto.

Portanto, como pode ser observado, tudo está no discurso. 0 porto Cais Mauá e seu projeto de requalificação é também uma construção no campo discursivo, onde os elementos se relacionam em um processo de articulação, buscando atingir suas demandas particulares em torno de um mesmo significante vazio, assim, modificando suas identidades de modo a se constituírem como totalidade dessa articulação, ou seja, num sistema discursivo. 


\section{Aspectos metodológicos}

Esse trabalho assume uma posição crítica de corrente pós-estruturalista e matriz pós-marxista sob uma abordagem qualitativa. A metodologia qualitativa emprega diferentes concepções filosóficas, estratégias de investigação, método e análise dos dados. Baseiam-se em dados de textos, entrevistas e imagens; é fundamentalmente interpretativo e permite ao pesquisador ter uma visão do fenômeno (Creswell, 2010).

Para atingir o objetivo proposto, utilizou-se a análise do discurso (AD) que trata de analisar, problematizando uma variedade de materiais e informações, tendo como conceitos-chaves para discutir o fenômeno, juntamente com as categorias analíticas da Teoria do Discurso de Laclau e Mouffe discutidas anteriormente. A análise do discurso permitiu conduzir o recorte que compõe o corpus discursivo, codificando o material e logo em seguida fazendo as análises a partir de questões norteadoras, articulando um conjunto de dados. Dessa forma, "a análise se concentra no contexto, na variabilidade, nas construções do texto e nos repertórios interpretativos usados neles" (Flick, 2013, p. 158).

A Teoria do Discurso abrange um conjunto de etapas que norteiam as análises. Glynos \& Howarth (2007), teóricos do discurso, desenvolveram algumas orientações de metodologia a partir do método da Retrodução e seus ciclos. Dessa forma, este trabalho utilizou o método uma vez que está alinhando a teoria do discurso. A Retrodução nas ciências sociais se baseia em três momentos relevantes: a problematização, a explicação retrodutiva (momento de intersecção) e a explanação a partir de uma argumentação persuasiva/intervenção. Ela permite a observação de uma hipótese inicial $\left(\mathrm{H}^{1}\right)$, onde a mesma é trabalhada, permitindo novas reflexões depois de teorizar sobre os discursos. Nesse caso, a hipótese inicial foi apontada na introdução do trabalho.

A problematização possibilita alguns questionamentos a partir da construção e interpretação do fenômeno estudado para assim, expandir o campo discursivo, envolvendo todo o fenômeno empírico. A explicação retrodutiva seria a explanação do fenômeno a partir de hipóteses melhoradas, ou seja, por ciclos retrodutivos reinterpretando as observações levantadas na problematização. A persuasão e intervenção é o momento conclusivo do trabalho, onde a teoria é mencionada e se traz uma argumentação a partir dos achados para convencer e propor intervenções numa literatura engajada (Oliveira et al., 2013).

No que diz respeito ao corpus de pesquisa, ele foi construído a partir das posições dos sujeitos políticos. Nesse sentido, foi preciso selecionar os sites que representassem conteúdos importantes, com profundidade e que ao mesmo tempo tivesse uma diversidade de vozes nas discussões sobre a tensão relativa à requalificação do Cais Mauá. Depois de uma pesquisa cuidadosa, foi montado o corpus contendo 184 arquivos conforme apresentado na Figura 02.

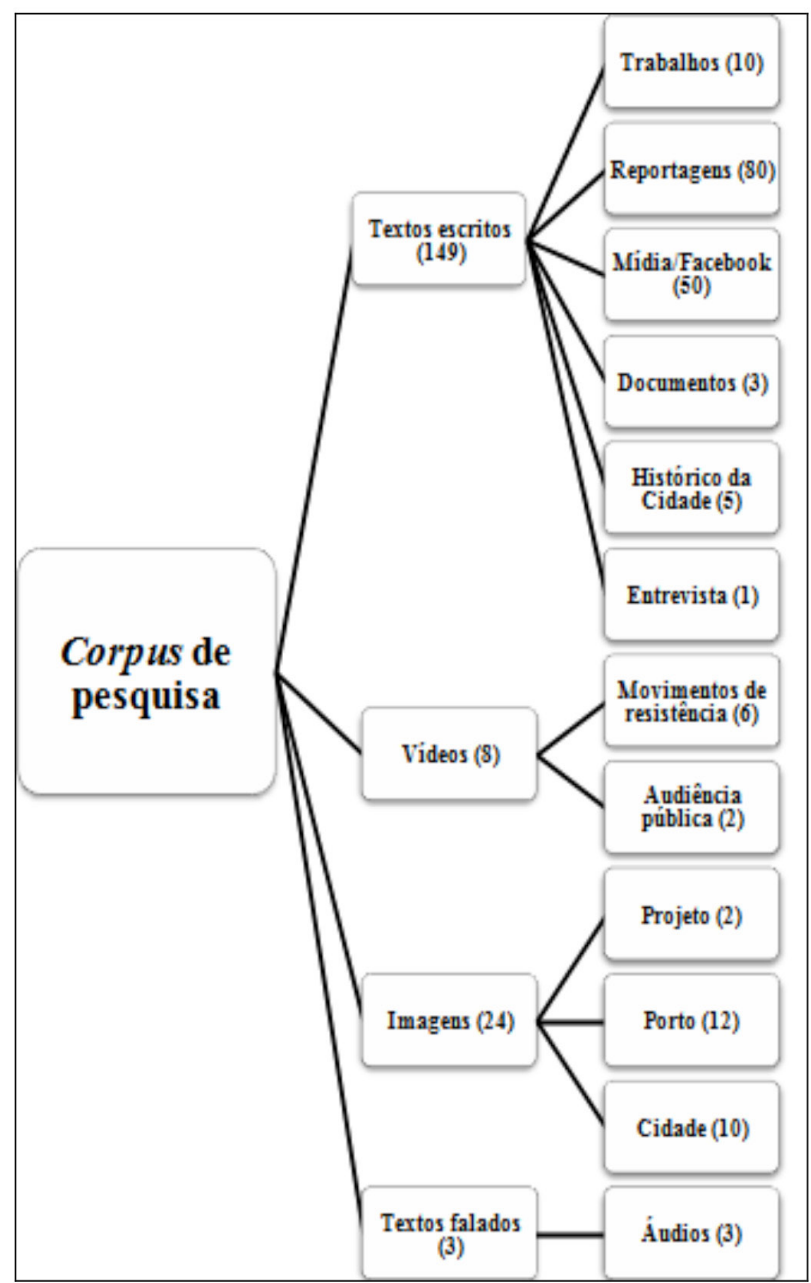

Figura 02 - Composicão do corpus de pesquisa. Fonte: Elaborado pelos autores (2016). 
As reportagens tiveram um recorte temporário entre março de 2015 até fevereiro de 2016, separadas e salvas na íntegra no formato PDF. As imagens foram relevantes para discutir o projeto, fazendo uma relação com a própria história do porto. Os documentos são referentes ao projeto na íntegra e ao "manifesto Mauá". Os áudios são entrevistas com representantes discutindo o projeto em um jornal local via rádio.

Para melhor organizar as reportagens, as mesmas foram analisadas sob dois pontos de vistas distintos que seria a partir do antagonismo. 0 primeiro ponto de vista foi sob a perspectiva do Estado e da iniciativa privada (grupo 1); o segundo ponto de vista foi sob a perspectiva das demandas que resistem ao projeto atual (grupo 2). 0 trabalho de análise se iniciou logo após a organização do corpus de pesquisa, onde os arquivos foram cautelosamente lidos e analisados na tentativa de localizar as possíveis categorias analíticas da teoria do discurso sobre a requalificação do Cais Mauá.

No que diz respeito a essas categorias analíticas da TD, o processo de significação se deu da seguinte forma: (1) Elemento; (2) Momento; (3) Articulação; (4) Ponto Nodal (5) Posição do Sujeito, (6) Cadeia de Equivalência, (7) Cadeia de Diferenças e (8) Significante Vazio. Os quais estão identificados e discutidos na sessão a seguir, fazendo as análises baseadas nas articulações que movimentam os diálogos: primeiramente da postura hegemônica e posteriormente da contra-hegemonia.

\section{Estruturas discursivas e articulações que movimentam os diálogos}

Essa sessão se debruça em apresentar trechos das reportagens que desvelam os discursos dos atores envolvidos na luta pelo espaço do Cais Mauá, bem como suas articulações no desenvolvimento de estratégias para o alcance dos objetivos grupais através dos ciclos retrodutivos. Isso significa que foram descritas as reflexões sobre as demandas do Cais Mauá enquanto discursos na tentativa de desvelar a hipótese inicial. Antes de adentrar propriamente nos trechos das noticias se faz necessário discutir os sujeitos políticos envolvidos no caso.

Para isso, foi realizado um mapeamento desses sujeitos que foram retirados do corpus de pesquisa.
A Figura 03 apresenta os atores encontrados através dos discursos nos arquivos da pesquisa.

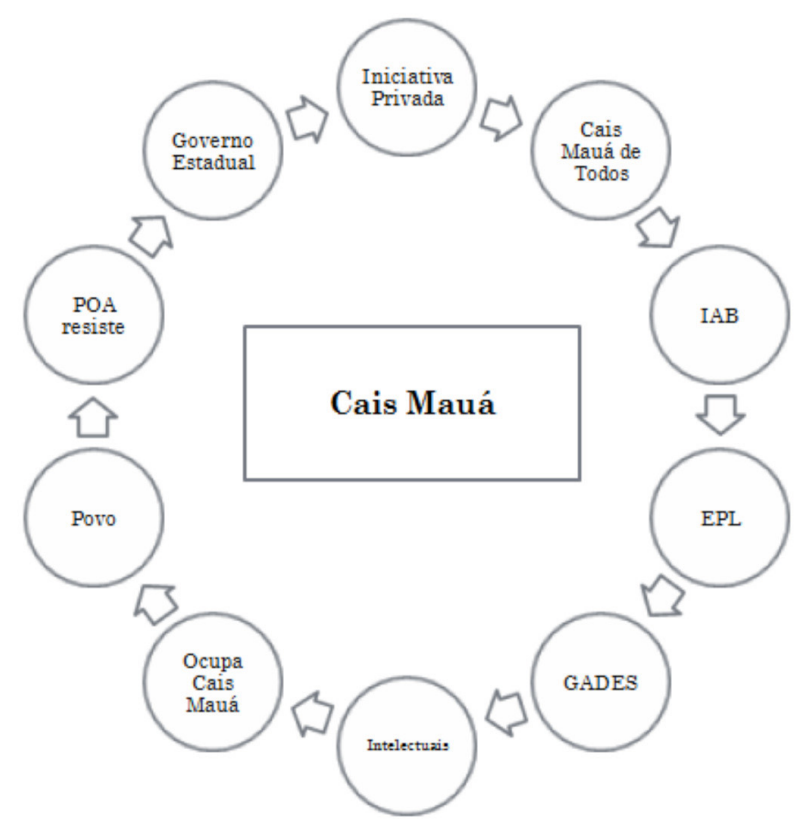

Figura 03 - Mapeamento dos sujeitos políticos.

Fonte: Elaborado pelos autores a partir do corpus de pesquisa (2016).

Observando a Figura 03 os sujeitos políticos emergem de uma série de demandas que foram observadas a partir do corpus de pesquisa. Percebemse que em torno do ponto nodal requalificação do Cais Mauá existe variadas posições de sujeitos identificadas por seus grupos: 0 governo estadual e a iniciativa privada fazem parte de um grupo que luta pela requalificação como está sendo proposta no projeto atual para preservação da memória e um "porto alegre".

Já os grupos: Cais Mauá de Todos, Ocupa Cais Mauá, POA resiste, IAB (Instituto dos Arquitetos do Brasil), EPL (Estudantes pela Liberdade), GADES (Gabinete de Desenvolvimento e Assuntos Especiais), intelectuais (sociólogos, especialistas em urbanismo, artistas, universidade federal) e a população se mostram contra o projeto e lutam por mais participação e transparência. Assim, pode-se perceber a pluralidade de vozes envolvidas com o Cais Mauá e como cada uma se posiciona em relação ao objeto.

Diante disso, o antagonismo está exposto e se observa um espaço sempre em disputa por um significado através dos discursos existentes. Os discursos, "a favor" e "contra", que organizam a discussão sobre o Cais Mauá, apresentam em suas estruturas 
cadeias de equivalências e de diferenças que os constituem e os diferenciam. Vale ressaltar que, por conta da limitação de espaço, optou-se por apresentar alguns trechos do corpus os quais estão identificados ao longo do trabalho.

\section{Postura Hegemônica: O Estado e o Grupo Cais Mauá Brasil S.A.}

Durante as análises foram identificadas duas cadeias de equivalências com poder de articulação na postura hegemônica que seria o Estado e a própria iniciativa privada. Elas se articulam de tal modo que formam uma cadeia individual. 0 discurso dessa cadeia defende uma requalificação por uma cidade "mais humanizada, mais orgânica e integrada com seu centro, que será como um coração pulsante".

No que diz respeito aos Momentos e as Articulações, observa-se que eles procuram criar pontos nodais com os significados ligados a convivência, reintegração, consumo cultural e melhorias na cidade. 0 Elemento nesse caso são as empresas que fazem parte do consórcio que se articula para formar os momentos. Abaixo são destacados os trechos do corpus que exemplifica o discurso hegemônico sobre a requalificação a partir de posições digamos que "positivas" para a sociedade como um todo. Nos trechos citados, os números identificados representam a codificação do processo de significação das categorias analíticas apresentadas na metodologia.

Inspirado em alguns dos mais bem-sucedidos projetos de revitalização do mundo, o novo Cais Mauá (8) chega para reintegrar os porto-alegrenses e seu Centro Histórico às águas do Guaíba (3) [...] Tudo isso com ZERO REAIS de investimento público. (Nome da Matéria: Um empreendimento para reintegrar a cidade com as águas do Guaíba. Fonte: http://vivacaismaua.com.br/o-projeto/. Publicado em 23/11/2015).

"Dizer que não vai ter torre ou shopping tudo bem. Então, não tem revitalização (5)", avisou o presidente (1) da NSG Capital. "O pessoal critica shopping e torres, mas essa é a contrapartida (3). Foi o que restou em $48 \%$ da área para financiar o resto", justificou Abreu. "Se for outro modelo, da onde vou tirar dinheiro?" (5), devolveu o executivo, indicando que a sustentação financeira da área de 187 mil metros quadrados seria difícil ao setor público. (Nome da Matéria: Sem torre se shopping Center, não tem revitalização, avisa acionista da Cais Mauá. Fonte: Jornal do Comércio. Publicado em 22/09/2015).

Dessa forma, as inferências que podem ser percebidas entendem que os significados ligados à convivência, à reintegração, ao consumo cultural e às melhorias na cidade fazem parte de um discurso baseado em atividades lucrativas e empreendedoras. Assim, as cadeias de equivalência se articulavam e tinham a necessidade inicial de convidar a sociedade para participação no projeto com o intuito de ter apoio, mas logo em seguida, o custo seria a construção de empreendimentos para atração turística (Harvey, 2005).

A partir disso, os Momentos (ações de divulgação, emissão de relatórios ambientais, intervenções políticas) discutem os Pontos Nodais inseridos no discurso na tentativa de convencimento da sociedade. Uma vez que o discurso em torno do Cais é construído socialmente, esse processo se torna carregado de antagonismos, expressos por meio de práticas sociais, políticas e culturais.

Diante do exposto, o Elemento (empresas do consórcio Cais Mauá Brasil S.A.) assume o discurso trazendo os empreendimentos privados em detrimento de melhor convívio, lazer e cultura. Assumindo assim, uma posição de sujeito: o Estado (investimento público) surge como um elemento muito bem articulado dentro da cadeia de equivalência quando é enfatizado que o mesmo terá "gasto zero" na execução da requalificação. Verifica-se então um aliado com bastante poder que compartilha significados comuns que os torna discursivamente com laços fortes e com interesses individuais particulares.

As famosas "Torres Gêmeas" que abrigam a sede central do Ministério Público do Rio Grande do Sul (MP_RS), na área administrativa de Porto Alegre - quase às margens do Guaíba, na altura da rótula das Cuias - ganharão duas novas irmãs em breve (2). 0 projeto (4) prevê 618 vagas para automóveis [...] (Nome da Matéria: Ministério Público projeta torres quadrigêmeas em área administrativa. Fonte: Jornal Já - Porto Alegre. Publicado em 05/11/2015). 
[...] o consórcio vencedor (5) da licitação para revitalizar o Cais Mauá não deve utilizar a totalidade do índice nas três torres que planeja construir. Segundo a assessoria de imprensa do empreendimento, serão 28,25 e 14 andares em cada uma - porém, não há confirmação da altura em metros porque o Estatuto de Viabilidade Urbanística (EVU) ainda não foi encaminhado à prefeitura municipal (1). 0 Plano Diretor de Porto Alegre estabelece que as edificações na cidade terão, no máximo, 52 metros de altura, porém, o projeto do Cais (4) obteve permissão da Câmara Municipal para ampliar esse limite. (Nome da Matéria: Torres projetadas para o Cais Mauá terão 28, 15 e 14 andares. Fonte: Jornal Já Porto Alegre. Publicado em 22/11/2015).

Um fato interessante ocorre depois que a Prefeitura é questionada pelos ativistas que resistem ao projeto. No trecho a seguir é possível observar a medida adotada para "beneficiar" um grupo em relação à execução do projeto.

Para contemplar os ciclistas (1), a Prefeitura (1) exigiu do empreendedor a construção de 8,7 quilômetros de ciclovias (2) - sendo 1,2 quilômetros na avenida Mauá. 0 investimento em ciclovias será de R\$120 milhões na restauração do conjunto de 11 armazéns tombados pelo município (3), e deverá ainda construir as novas sedes da Superintendência de Portos e Hidrovias (SPH) e o quartel-general dos Bombeiros (3), que atualmente ocupam áreas do cais. (Nome da Matéria: Cais Mauá protocola contrapartidas de R\$36 mi na Prefeitura. Fonte: Jornal Já - Porto Alegre. Publicado em 24/04/2015).

Vários questionamentos surgem com essa medida, pois antes o que parecia uma cadeia de equivalência muito bem articulada, parece existir agora uma cadeia de diferença que desarticula o discurso hegemônico. Entretanto, não se pode inferir sobre isso justamente por existir interesses próprios nas sedes do SPH e no quartel general dos bombeiros.

Dessa forma, o que pode ser observado é que o significado que gira em torno do Cais Mauá e sua requalificação é articulado enquanto um progresso para a população porto alegrense (Harvey,
2005), apesar de algumas notas contraditoras como foi percebido na análise. A seguir foi analisada a posição contra hegemônica a partir de seus discursos.

\section{A contra-hegemonia, conflitos e [R] existência: A busca pela hegemonia e o resgate da memória cultural}

De acordo com as análises foram observadas 8 cadeias de equivalências que fazem parte da postura contra- hegemônica: 1) Cais Mauá de Todos; 2) Ocupa Cais Mauá; 3) POA resiste; 4) IAB; 5) EPL; 6) GADES; 7) intelectuais; 8) povo. Todos esses grupos são contra o projeto atual vigente e lutam por outra possibilidade de requalificação. Os três primeiros mais articulados e os outros menos articulados.

A lógica de equivalência entre esses grupos consiste na defesa de maior transparência e democracia, se posicionando contra qualquer obra no local que elitize o espaço. Os Momentos e as Articulações na contra-hegemonia procuram criar pontos nodais com significados e lutam pela hegemonia através de três pontos: A) resistência; B) estratégias e ações; e C) outras alternativas. Assim as análises foram feitas considerando esses pontos como pode ser observado nos trechos a seguir, além da fala de um líder ativista que faz parte do grupo Cais Mauá de Todos, a qual está identificada como SE (sujeito entrevistado).

a) Resistência:

0 modelo proposto é um plano de negócio (4) que serve para especulação imobiliária da área mais nobre do centro histórico de Porto Alegre. 0 que significa dizer que a construção de três torres comerciais, um shopping center e 5 mil vagas de estacionamento em plano Cais Mauá despreza totalmente os impactos ambientais e urbanos desses equipamentos (3), no que diz respeito ao meio ambiente, mobilidade urbana, economia e identidade histórica. "Não se trata de um movimento anticapitalista, mas a área pública tem que ser pública (6)". (Nome da Matéria: a polêmica revitalização do cais Mauá. Fonte: Jornalismo Ambiental. Publicado em 15/07/2015). 
O tumulto foi protagonista da audiência pública (3) realizada na noite desta sexta-feira, quando a empresa Cais Mauá do brasil apresentou o Estudo de Impacto Ambiental (EIA-Rima) da obra de revitalização do cais do porto (2). 0 encontro (3), marcado por vaias a quem defendia o projeto, e por palmas para quem o criticava, foi realizado no Grêmio Náutico União, em Porto Alegre com apoio do GADES. O relatório apresentado pela empresa responsável pelo projeto é apenas uma das fases necessárias para a obtenção das licenças (2) que permitirão o início da obra. (Nome da Matéria: Cais Mauá: tumulto marca apresentação do estudo de impacto ambiental. Fonte: Jornal Zero Hora. Publicado em 18/09/2015).

Como podem ser observados todos esses trechos indicam a revolta dos grupos envolvidos e as inferências feitas nas análises discutem que os significados fixados são pautados em democracia, transparência e preservação da memória histórica do local a fim de manter a identidade. Os conceitos de elitização e empresariamento estão sempre circulando nas estruturas discursivas dos sujeitos envolvidos na contra-hegemonia. Na obra de Laclau, o sujeito resiste e interage nos processos que constituem as relações sociais, e dentro desse movimento articula-se e transforma-se, criando novas formas de ver o mundo (Laclau \& Mouffe, 2015).

É perceptível a luta pelo significante vazio a partir de articulações e as variadas posições do sujeito. Laclau menciona que o sujeito resiste e se articula nos procedimentos que compõem as relações sociais, e dentro desse movimento articula-se e transforma-se, criando novas formas de ver o mundo (Santos \& Mello, 2014). Logo em seguida, aparecem os Momentos através de ações e estratégias que sistematizam pontos nodais inseridos no discurso. A seguir o trecho da entrevista realizada com uma ativista que resiste ao projeto atual:

0 que mais tem causado polêmica é a construção de um shopping center e 2 ou 3 torres (nem eles sabem) de $100 \mathrm{~m}$ na beira do Guaíba (5). Para "dourar a pílula", o consórcio que ganhou a licitação (que também tem problemas), investe pesado na propagando (5) da restauração dos bens tombados pelo IPHAN e pelo Município de Porto Alegre. 0 atual projeto (4) foi concebido como um plano de negócios [...] Mas o que a população quer (6), a restauração dos armazéns, seria feito com apenas R\$ 43 milhões. Pode-se ver que o objetivo é o lucro. (SE - entrevista via e-mail realizada no dia 14/01/16).

Quando questionada sobre o que ocorrerá em relação ao valor imobiliário das propriedades existentes no bairro, após a revitalização do Cais, a ativista responde dessa forma:

Certamente, os valores dos imóveis e aluguéis tendem a crescer, pela elitização que é pretendida para o local (8). Acredito (5) que muitas pessoas que ainda moram no centro deverão deixar o bairro. (SE - entrevista via e-mail realizada no dia 14/01/16).

Pode se observar a posição política de um grupo através de um líder ativista demonstrando seu discurso diante da requalificação da forma que está sendo colocada. Ela se apresenta como um Elemento e cria Momentos a partir de ações, formando variadas articulações com o objetivo de chegar a hegemonia, dando significado ao significante vazio por meio do ponto nodal requalificação.

A análise do discurso dos que estão a favor do projeto atual de requalificação se apresenta como um articular em favor do sentido de que a requalificação é relevante para o progresso do estado. Como está sendo observado, esse discurso disputa espaço com aqueles que são contra o projeto da maneira que está sendo imposta, sem levar em consideração o sentir da cidade (Lefebvre, 2008; Harvey, 2005). Nesse sentido, esses diálogos são práticas articulatórias que pretendem fixar sentidos em torno do Cais.

\section{b) Estratégias e ações:}

O movimento ocupa o Cais Mauá (1) realizou na tarde desta sexta-feira o debate (3) "A cidade que queremos", no Santander Cultural. Mais de cem pessoas lotaram a Sala Leste do Santander Cultural. Outros tantos ficaram do lado de fora. Ao final, os participantes fizeram uma caminhada (3) que deveria ser encerrada na beira do Guaíba. (Nome da Matéria: Barrados no cais. Fonte: Jornal Já - Porto Alegre. Publicado em 13/11/2015). 
Integrantes do coletivo POA resiste (6) protocolaram na tarde desta segunda-feira (11) nova representação no Ministério Público do Rio Grande do Sul (MP-RS) pedindo a apuração de irregularidades no processo licitatório da revitalização do Cais Mauá (8). (Nome da Matéria: Movimentos pedem que MP investigue corrupção em contratos do Cais Mauá. Fonte: Jornal Já - Porto Alegre. Publicado em 11/01/2016).

O processo articulatório é observado nas reportagens apresentadas identificados como Momentos a partir da teoria do discurso de Laclau e Mouffe. 0 que se infere de forma geral é o alto grau de articulação dentro do discurso contra hegemônico. Dessa forma, essa cadeia de equivalência compartilha de muitos significados comuns, o que os torna politicamente fortes.

0 "progresso" e uma "cidade para todos" como foi observado surge no discurso hegemônico, mas esse tipo de progresso traz também consigo exclusão, concentração de renda, e subdesenvolvimento, agredindo e restringindo direitos humanos essenciais (Santos \& Mello, 2014; Cordeiro \& Mello, 2013). Nessa disputa ainda existem os manifestantes que apresentam propostas alternativas como forma de gerar significado para uma parte da população que não é contemplada na postura hegemônica.

c) Outras alternativas:

No próximo sábado (18) o Coletivo Cais Mauá de Todos (6) formado por porto alegrenses descontentes com a concessão do antigo porto da Capital à iniciativa privada, apresentará um projeto de intervenção (3) arquitetônica e urbanística alternativo ao proposto pelo consórcio vencedor da licitação. (Nome da Matéria: Ativista propõem projeto alternativo para o Cais Mauá. Fonte: Jornal Já - Porto Alegre. Publicado em 15/12/2015).

Como forma de fazer ativa sua voz, a contra hegemonia cria outras alternativas, trazendo projetos complementares que visam a participação e a transparência. Isso é um modo de criar significados para o significante vazio através do ponto nodal. Ainda vale salientar a contribuição das redes sociais nesse debate.
Movimentos como "Cais Mauá de Todos" \#OcupaCaisMauá e "POA resiste" são atuantes de forma fervorosa nas redes, mantendo os internautas atualizados sobre o andamento das manifestações. Esses três grupos são articulados de tal forma que compõem uma só cadeia de equivalência, colocando suas estratégias em constante articulação com os objetivos comuns. Em uma dessas páginas, as curtidas chegam há quase 6 mil, mas apesar do número os participantes mantém frequentes atos nas ruas para buscar as pessoas e as respostas.

Apesar da articulação na contra-hegemonia, ainda é possível observar algumas individualidades deixando transparecer as diferenças. Alguns intelectuais, a classe dos arquitetos e parte da população muitas vezes parecem apáticos no momento de fazer valer seu discurso. Nas análises foi possível observar em algumas situações que os arquitetos se posicionavam contra a requalificação e outras vezes eram a favor porque isso geraria mais emprego e trabalho para eles e parte da população que em algumas situações resiste e em outras pedem o aceleramento da requalificação para usufruir o local.

Dessa forma, a falta da Lógica de Equivalência aparece como uma lógica de diferença que muitas vezes desarticula o significado de "preservação cultural, ambiental e identitária", desocupando suas posições na geração de significado para o significante vazio. Entretanto, ainda se pode inferir nas análises que existiu uma medida tímida de articular o significado em torno do ponto nodal.

Diante do exposto, compreende-se que as disputas pelos sentidos que incidem no campo social se apresentam como arenas discursivas antagônicas em torno da requalificação do Cais Mauá. Esses antagonismos e as resistências fazem parte do discurso em torno do Cais e são relevantes na teoria de Laclau e Mouffe, nas quais o autor considera como campo de discursividade. "A relação antagônica se estabelece na medida em que a presença do 'outro' não permite que o 'eu' seja completamente 'eu'" (Pinto, 1999, p. 84). Nesse sentido, foi criada uma representação gráfica onde buscou-se ilustrar as cadeias de equivalência e lógicas de diferenças presente em torno do ponto nodal requalificação do Cais Mauá (Figura 04). 

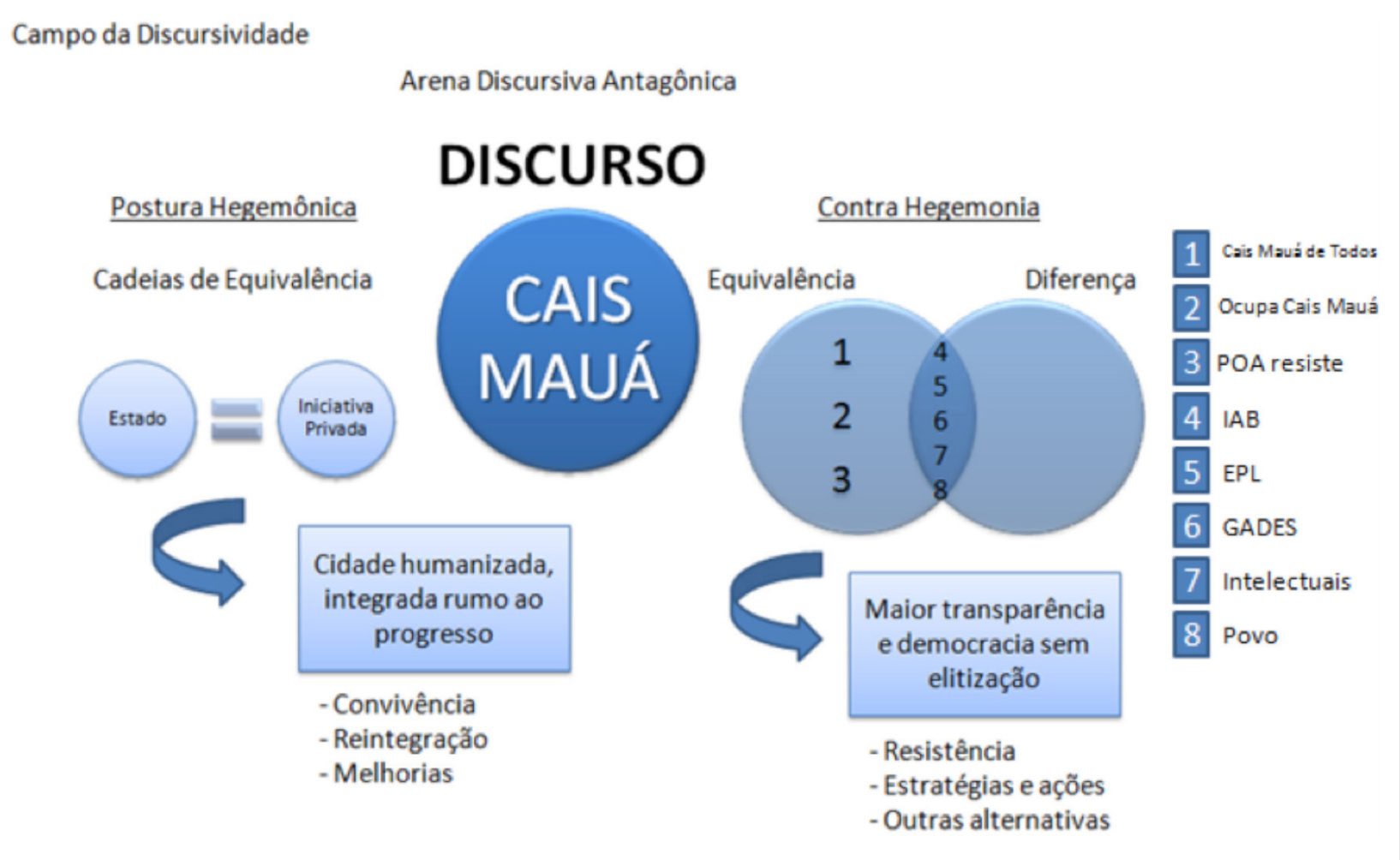

Figura 04 - Cadeias de equivalência e diferença em torno do Cais Mauá. Fonte: Elaborado pelos autores (2016).

A interpretação da representação gráfica denota o campo da discursividade por meio da arena discursiva antagônica e os conceitos que fazem parte da Teoria do Discurso. No centro, o próprio espaço de disputa, o Cais Mauá e nas laterais os sujeitos políticos em busca de trazer significado ao espaço do significante vazio.

Na postura hegemônica, a presença do Estado e da empresa numa cadeia de equivalência com seus discursos de convivência, reintegração, cidade humanizada com rumo ao progresso. 0 outro lado antagônico representado pela contra- hegemonia, denotando algumas cadeias de equivalências com discursos de maior transparência e democracia sem elitização do espaço através de resistências, estratégias e outras alternativas de requalificação.

Além de algumas cadeias de diferenças devido a interesses individuais e desarticulações. Por isso, os números 4, 5, 6, 7 e 8 representado pelos grupos políticos estão na intersecção do globo, demonstrando em alguns momentos equivalências e em outros as diferenças. Essa seção é finalizada com mais um discurso na busca pela hegemonia discutida em uma das páginas oficiais dos ativistas no Facebook:

Após o encontro onde foram ouvidas diversas entidades da sociedade civil (1), definimos (5) a linha de preparação para a audiência pública $(2,3)$ de março, dia 16, na Assembleia Legislativa do RS. A prefeitura e o estado (1) se tornaram coadjuvantes de um projeto (4) que visa usar da necessidade de revitalização do Cais (8), que ninguém discorda, para a especulação imobiliária e lucro de poucos. Pouco se conhece sobre os "donos" da concessão, não tem em seu portfólio nenhuma realização de qualquer empreendimento. Pouco foi feito até agora para tornar transparente o projeto (3) do cais [...]. (Fonte: Fala de integrante do movimento "Cais Mauá de Todos" no Facebook. Publicado em 17/02/2016).

Como demonstrado no trecho à luta pelo preenchimento do significante vazio é notável com um discurso de manter a paisagem da cidade no sentido 
de preservação, a revolta é visível contra a posição hegemônica e isso mostra que essa batalha ainda está distante de ser resolvida diante do contexto atual. 0 exemplo dessas intervenções e conflitos no Cais Mauá é também percebido em outras realidades que mantém a mesma natureza na tentativa de criar significados para o espaço urbano.

Zancheti, Somekh e Fregonezi (2016) desenvolveram uma pesquisa comparando seis centros históricos no Brasil e dentre eles o centro histórico de Porto Alegre. No trabalho é possível perceber uma série de conflitos que envolvem a temática da produção do espaço urbano e o direito a cidade: o caso de São Luís, Recife, Salvador, São Paulo, Rio de Janeiro e Porto Alegre. Em todos os casos são percebidas as multiplicidades de vozes que envolvem a problemática, bem como uma discussão que relaciona a cidade como produto e democracia.

\section{Para além das conclusões: O discurso continua [...]}

Foram percebidas duas posições discursivas: os que estavam propondo a requalificação do Cais e os que eram contra a requalificação do jeito que estava sendo discutida. Os sujeitos envolvidos buscam através das articulações hegemonizar seus valores por meio de seus discursos e ações. Essa dualidade de questionamentos e opiniões acabam por mostrar uma lógica polarizada e maniqueísta "do bem contra o mal", entretanto, essa não foi a intenção desse trabalho, pois apenas foram observadas posições antagônicas e os discursos em torno do Cais Mauá, problematizando-os.

Foram exploradas as noções das cadeias de equivalências e as lógicas das diferenças nas relações antagônicas, na abordagem da Teoria do Discurso cujas questões estabeleceram os pontos de reflexões abordados. Pelo exposto, a requalificação do jeito que está sendo proposta não considera os aspectos sociais da própria população porto alegrense, uma vez que, a construção dos empreendimentos acaba por excluir ao invés de incluir.

Dessa forma, volta-se a hipótese inicial e depois de realizadas as análises surge uma nova reinterpretação. Sugere-se agora que o discurso (através das práticas) da postura hegemônica quer, além de trazer um espaço atrativo e de convivência, trazer principalmente lucro através do espaço e seus empreendimentos. Ou seja, ficou perceptível que a contra hegemonia é contra esse significado, questionado a postura. Os discursos aqui apresentados demonstram a busca por significação pautada no conceito discutido por Harvey (2005) sobre empresariamento urbano e cidade-mercadoria. É interessante discutir políticas públicas para que o espaço urbano não se transforme numa esfera capitalista.

Essa nova interpretação não explica de forma definitiva o fenômeno, pois os ciclos retrodutivos continuam no campo da discursividade e a complexidade em torno dos conceitos de cidade e da Teoria do Discurso não permite verdades absolutas e respostas definitivas. Como o discurso é considerado uma prática, essa hipótese está sempre orbitando em meio aos novos contextos diante do fato.

Pode-se considerar que o discurso sobre o Cais Mauá está dividido nessas frentes de batalha e nessa luta pela hegemonia. Apesar de a requalificação estar em processo de andamento, muitos grupos não mostram consenso na execução até os dias atuais. Nesse sentido, Harvey (2013) quando discute sobre o Direito à Cidade compreende que não pode ser observado como um direito individual, pois existe um esforço coletivo ao redor de solidariedades sociais.

0 mesmo acontece com Lefebvre (2008) onde é realizado um paralelo entre as classes dominantes e as classes operárias. Para o autor, no tecido urbano surge uma desordem na cidade, com a compreensão de que a classe operária seja expulsa do centro, diminuindo o conceito de "habitar". Nesse caso, a cidade é discutida sob a ótica de uma grande rede tecnicamente socialmente e politicamente, onde o capital e o Estado estabelecem suas relações. Harvey (2005) faz também uma análise marxista desse espaço numa relação entre o Estado e o próprio capitalismo, trazendo contribuições para uma analise espacial.

Dessa maneira, o esboço de resposta a pergunta de pesquisa se pauta em refletir sobre a seguinte questão: tanto o discurso hegemônico como a postura da contra-hegemonia possuem suas peculiaridades, mas compartilham algo em comum: o conceito de cidade. Por um lado um conceito de cidade baseado em mega estruturas, grandes empreendimentos e valor econômico agregado rumo ao progresso, e do outro lado um modelo baseado em participação, transparência, convívio e preservação 
através de resistência, estratégias e outras alternativas. A requalificação do Cais Mauá aparece como apenas uma fração desse discurso maior sobre a questão da mobilidade urbana, a privatização de espaços públicos, urbanismo crítico, planejamento urbano, a intervenção na orla e no perfil da cidade e o potencial dano ao patrimônio cultural.

Portanto, a requalificação do Cais Mauá representa politicamente um antagonismo sobre as cadeias de significação que envolve os temas de empresariamento urbano, utilização dos espaços públicos e o direito a cidade. Por fim, vale salientar que a luta estabelecida no Cais não tem previsão de término, e para fins desse trabalho as análises se deram até determinada data, entretanto, as notícias, polêmicas, resistências, notas de repúdio, ações e articulações continuam a fazer parte da arena discursiva na disputa por significados, por este motivo, o discurso continua. 0 futuro do Cais Mauá permanece indefinido, denotando a continuação dos conflitos em busca de trazer significados inerentes aquele espaço público.

A teoria-método utilizada, juntamente com a retrodução permite a elaboração de uma teoria ao fim do processo, entretanto não foi desenvolvida justamente por conta dessa limitação temporal. Apesar de o trabalho ter se dedicado em atender ao objetivo e reinterpretado a hipótese inicial, todo o processo da retrodução não foi completo, abrindo a possibilidade para futuros trabalhos acadêmicos, visto que o objeto é amplo, onde o espaço e a luta pelo significado continuam entre conflitos, discursos e [R] existência.

\section{Referências}

Cardoso, J. J. (2007). Patrimônio ambiental urbano e requalificação: contradições no planejamento do núcleo histórico de Santos (Tese de Doutorado). Programa de Pós-Graduação em Geografia Humana, Universidade de São Paulo, Faculdade de Filosofia, Letras e Ciências Humanas, São Paulo.

Cavalheiro, M. H. (2008). Manifesto Mauá: uma costura urbana no centro de Porto Alegre (Trabalho de Conclusão de Curso). Curso de Arquitetura e Urbanismo, Universidade Federal do Rio Grande do Sul, Faculdade de Arquitetura, Porto Alegre.
Coelho, K. S. (2012). A resistência à nova proposta de plano diretor apresentada pela prefeitura municipal de Florianópolis: uma análise das práticas alternativas de organizar (Tese de Doutorado). Programa de Pós Graduação em Administração, Universidade Federal de Santa Catarina, Centro sócio - Econômico, Florianópolis.

Cordeiro, A. T., \& Mello, S. C. B. (2010). Teoria do discurso laclauniana: uma mediação entre teoria crítica e prática política. Anais do Encontro Nacional da Anpad, Rio de Janeiro.

Cordeiro, A. T., \& Mello, S. C. B.(2013). Crise de sentido no capitalismo avançado: uma abordagem discursiva. Recife: Edupe.

Creswell, J. W. (2010). Projeto de pesquisa: métodos qualitativo, quantitativo e misto. 3.ed. Porto Alegre: Artmed/ Bookman.

Del Rio, V. (1993). Revitalização de Centros Urbanos: o novo paradigma de desenvolvimento e seu modelo urbanístico. Revista Pós - revista do programa de pós-graduação em arquitetura e urbanismo. FAUSP.

Flick, U. (2013). Introdução a Metodologia de Pesquisa: um guia para iniciantes. Porto Alegre: Pensa.

Foucault, M. (1996). A ordem do discurso. São Paulo: Loyola.

Harvey, D. (2013). A condição pós-moderna: uma pesquisa sobre as origens da mudança cultural (23a . Ed). São Paulo: Edições Loyola.

Harvey, D. (2005). A produção capitalista do espaço. São Paulo: Annablume.

Kruse, F. (2011). Intervenções em centros urbanos: o caso da antiga área portuária de Porto Alegre (Dissertação de mestrado). Programa de Pós-Graduação em Planejamento Urbano e Regional, Universidade Federal do Rio Grande do Sul, Porto Alegre.

Laclau, E. (2011). Emancipação e diferença. Rio de Janeiro: EdUERJ.

Laclau, E. (1993). Nuevas reflexiones sobre la revolución de nuestro tiempo. Buenos Aires: Nueva Visión.

Laclau, E., \& Mouffe, C. (1985). Hegemony and socialist strategy. London: Verso.

Laclau, E., \& Mouffe, C. (2015). Hegemonia e estratégia socialista: por uma política democrática radical. São Paulo: intermeios; Brasília. 
Lefebvre, H. (2008). O direito à cidade. Centauro Editora.

Maziviero, M. C. (2016). Entre a recuperação patrimonial e a questão da moradia: projetos de renovação urbana para o centro de Santos. URBE - Revista Brasileira de Gestão Urbana, 8(2), 181-196.

Mendonça, D. (2009). Como olhar "o político" a partir da teoria do discurso. Revista Brasileira de Ciência Política, $1,153$.

Mendonça, D. (2010). Teorizando o agonismo: crítica a um modelo incompleto. Revista Sociedade e Estado, 25(3), 479-497.

Mouffe, C. (2005). On the political. London: Routledge.

Oliveira, G.; Oliveira, A., \& Mesquita, R. (2013). A teoria do discurso de Laclau e Mouffe e a pesquisa em Educação. Educação e Realidade, 38(4), 1327-1349.

Pinto, C. R. J. (1999). Notas a propósito de Ernesto Laclau. Revista de Ciências Sociales, 15, 36-48.

Prefeitura de Porto Alegre, (2015). Histórico da cidade. Recuperado em 28 de novembro de 2015, de http://www2.portoalegre.rs.gov.br/turismo/default. php?p_secao $=257$

Santos, J. M. L.; Mello, S. C. B. (2014). Os significados de Belo Monte no discurso das mídias sociais. Revista Comunicação, Mídia e Consumo. São Paulo.

Silva, C. C. G.; Batista, M. M.; Mello, S. C. B. (2014). A teoria do discurso de Laclau e Mouffe. In: S. C. B. Mello (Org.). Construção Social da Tecnologia e Teoria do Discurso. Recife: Editora UFPE.

Souza, C. F. (2008). Plano Geral de Melhoramentos de Porto Alegre: o plano que orientou a modernização da cidade. Porto Alegre: Armazém Digital.

Vieira, O. A. D. (2011). As revitalizações dos espaços portuários de Purto Madero - Buenos Aires - e do Cais Mauá - Porto Alegre - e suas relações com o entorno. Por uma análise de aproximação (Dissertação de Mestrado). Programa de Pós-Graduação em Geografia, Universidade Federal do Rio Grande do Sul, Instituto de Geociências, Porto Alegre.

Vieira, O. A. D. (2012). A revitalização do cais Mauá - por uma outra possibilidade. Revista Rosa dos ventos-Turismo e Hospitalidade, 4(1).
Zancheti, S.; Somekh, N., \& Fregonezi, B. (2016). Revitalização urbana no Brasil comparando seis centros históricos. Fórum Patrimônio: Ambiente Construído e Patrimônio Sustentável, 8(1).

Submissão: 20/06/2016

Received: $20^{\text {th }}$ June 2016

Aprovação: 05/10/2016

Approved: $05^{\mathrm{h}}$ October 2016 